\title{
The Role of Ovarian Varicose Veins and Varicocele in Cancer and Venous Thrombosis
}

\section{Pacheco $\mathrm{KG}^{*}$, de Oliveira $\mathrm{MRF}^{2}$ and Pacheco $\mathrm{MF}^{3}$}

${ }^{1}$ Sociedade Brasileira de Angiologia e de Cirurgia Vascular, Brazil

${ }^{2}$ Colégio Brasileiro de Radiologia, Brazil

${ }^{3}$ Dr. Kennedy Pacheco's Private Practice, Brazil

${ }^{*}$ Corresponding author: Pacheco KG, Sociedade Brasileira de Angiologia e de Cirurgia Vascular, Brazil, Tel: +55-21-998118965, E-mail: kennedy-gp@uol.com.br

Citation: Pacheco KG, de Oliveira MRF, Pacheco MF (2018) The Role of Ovarian Varicose Veins and Varicocele in Cancer and Venous Thrombosis. J Gynecol Res 4(1): 105. doi: 10.15744/2454-3284.4.105. doi: 10.15744/2454-3284.4.105

Received Date: December 25, 2017 Accepted Date: April 10, 2018 Published Date: April 12, 2018

\begin{abstract}
Varicose veins next to the testicles and the ovaries are associated with oxidative stress, which can change the phenotype of germinating glands, provoking abnormalities in the hypothalamic-pituitary-gonadal axis. This creates an interference that can express itself in the form of gene mutations in patients with cancer and venous thrombosis. In this study, we made it our goal to evaluate the prevalence of ovarian varicose veins and varicocele in patients with cancer and venous thrombosis and to further investigate this association. In order to achieve this objective, 54 patients with cancer and 98 patients in the control group diagnosed with venous thrombosis were included in this study. All of these patients were examined through ultrasound with vascular Doppler as a means to investigate varicocele in men and ovarian varicose veins in women. Out of a total of 14,800 patients, 152 with cancer and venous thrombosis were selected (1.02\%). The group with cancer presented a significantly $(\mathrm{p}=0.0029)$ higher proportion of varicose veins $(96.3 \%)$ next to the germinating glands than the group with venous thrombosis $(84.7 \%)$.
\end{abstract}

Keywords: Varicose Veins; Varicocele; Cancer; Venous Thrombosis

\section{Introduction}

Varicocele characterizes itself in the form of dilated, congested and tortuous veins. It is extensively referred to as "varicose veins next to the testicles", and it is a phenomenon that is found in $15 \%$ of adult men [1]. There is an association between varicocele and testicular dysfunction, and it has been seen to alter hormone production, cause semen abnormalities, provoke testicular atrophy and ultimately change the phenotype of the testicular gland $[2,3]$.

Scientists support the hypothesis that hydrostatic pressure in varicose veins next to the testicles decreases microcirculation, inducing damage in germinating cells and in the testicular stroma [4]. In some infertile patients, varicocele can be a cause for imbalance in the hypothalamic-pituitary-gonadal axis and for the reduction of testosterone levels in the peripheral blood [5-7].

Recent studies have shown that male infertility and semen abnormality increase the risk of cancer and venous thrombosis [8,9]. It has also been discovered that varicocele is the most common cause of infertility in men [10,11].

Similar to varicocele in men, ovarian varicose veins also characterize themselves in the form of dilated, tortuous and congested veins next to the ovarian gland, often causing chronic pelvic pain and a feeling of heaviness in the pelvis in women [12,13]. Studies have shown that ovarian varicose veins are prevalent in 12 to $15 \%[12,14]$ of the general female population.

Increased oxidative stress (OS) in varicose dilations next to the testicles can reduce fertility in patients with varicocele and change this gland's phenotype [15-18]. Similarly, two experimental studies performed in female rats have demonstrated that increased OS present in ovarian varicose veins provokes histologic damage in the ovaries and suggests a negative effect related to fertility [19,20].

While it is true that physiological levels of OS in the ovaries are necessary for several biological functions, high levels can impair oocyte maturation [21], provoke DNA fragmentation in sperm and be related to the birth of children with embryonic defects and cancer [22-24].

The change in phenotype with morphologic as well as hormonal production alterations in both the ovaries [25] and the testicles [26] is associated to the increase in risk of cancer and venous thrombosis [8,9,25-28]. It has also been reported that ovarian varicose veins can evolve with venous thrombosis, pulmonary embolisms [29,30], and infertility [19,20]. 
Moreover, researchers have also evidenced that female infertility may increase the risk of cancer and other pathologies [31,32].

In patients with ovarian varicose veins, it has been observed that the level of female hormones in the blood collected from veins of the inguinal region was twice as large as the levels present in the blood collected from arm veins [33]. These women tend to have a larger uterus and more ovarian cysts [34].

Galkin et al have described 19 cases of patients who were considered infertile, out of which 14 became pregnant after treating their ovarian varicose veins through embolization. These results suggest the possibility of an association between infertility and this pathology [35], in a way similar to that in which it is associated to varicocele [15-18].

The diagnosis of varicocele [36-38] and ovarian varicose veins [14] can be made through ultrasound technology and vascular Doppler. However, the golden standard method for the diagnosis is the phlebography of pelvic veins in women [39-41] as well as in men [42].

Studies show that when comparing ultrasonography to phlebography, the sensitivity in women [39-41] was of 96.2\% and the specificity was of $100 \%$. In men, the sensitivity was of $98 \%$ and the specificity was of $100 \%$ [42].

In light of the fact that ovarian varicose veins and varicocele with increased concentrations of OS cause changes in these glands' phenotype, we have decided to perform a retrospective study to investigate the prevalence in these two pathologies.

\section{Materials and Methods}

The sample was selected from a universe of 14,800 patients that were treated in my private practice specialized in vascular surgery, from the 1st of April 2012 to the 30th of June 2015, in Rio de Janeiro - Brazil. 152 (1, 02\%) male and female patients diagnosed with cancer and venous thrombosis were selected. 98 of them were diagnosed with venous thrombosis and 54 with cancer. This study followed the Helsinki criteria and the rules of the medical code of ethics. All patients were informed about the study and signed their consent, giving authorization. The 54 patients who had cancer had their diagnosis confirmed by biopsy in hospitals with oncological reference, just as the patients with venous thrombosis were diagnosed by vascular eco-color Doppler and treated by specialists in this pathology.

The patients were examined by a radiologist specialized in image diagnosis and ultrasound and were monitored by the authors of this study. For the ultrasound, we worked with an instrument by Phillips, HD 7, in Rio de Janeiro, Brazil, with a C8-4v minuscule system, with a transvaginal transducer of 4 to $8 \mathrm{MHz}$ for the ovarian varicose veins in women. We also used a $7.5 \mathrm{MHz}$ transducer for varicocele in the scrotum in men. Before the exams, the female patients all excreted all liquid from their bladders and lay down in supine position. Female patients bent their knees and male patients stretched their knees. The transvaginal transducer was coated with a lubricated condom and introduced into the vaginal canal of the patient, which allowed identification of the ovaries and the vascular structures of each adnexal region. The researchers were looking to identify anechoic, circular, linear and non-pulsatile structures in the broad ligament of the uterus. When anechoic structures were found with a diameter equal to or larger than $4 \mathrm{~mm}$, the color scale and pulsed-wave Doppler were used. We simulated three possibilities in the diagnostic investigation of ovarian varicose veins.

There is no absolute consensus in medical literature regarding the minimum diameter of varicose dilations next to the ovaries [38-41] Since values vary from 4.0 to $7.0 \mathrm{~mm}$, in order to define constraints for diameter values in our study, we adopted 3 criteria. The first criteria establishes the parameters for this diameter to be from 4.0 to $4.9 \mathrm{~mm}$, criteria 2 establishes it as $5.0 \mathrm{~mm}$ to $5.9 \mathrm{~mm}$ and criteria 3 establishes it as over $6.0 \mathrm{~mm}$. Significant reflux was defined as the retrograde flux lasting equal to or longer than $0.5 \mathrm{~s}$, [43-45] monitored by Doppler pulse wave.

The transducer was introduced cautiously into the topography of the inguinal channel in men, where the artery was identified. Then, the spermatic veins in the external orifice of this channel were also identified and followed to the posterolateral region of the scrotum, where the veins of the venous plexus pampiniform were found. This was how the visualization of these structures (in mode B) and measurement of the diameter were done. Next, we used the scale of colors with Valsalva maneuvers and the pulsed Doppler effect to confirm or discard the presence of the varicose veins. Once again, we simulated three possibilities in the diagnostic investigation of varicocele, since there is no absolute consensus in medical literature regarding the minimum diameter of varicose dilations next to the testicles. It was considered in veins with diameter between $2.0 \mathrm{~mm}$ and $2.49 \mathrm{~mm}, 2.5$ to $2.99 \mathrm{~mm}$, and above $3.0 \mathrm{~mm}$, with reflux greater than or equal to 0.5 seconds in the veins next to the testicle [36-38].

\section{Statistical analysis}

The descriptive analysis presented in table form the observed data expressed by the frequency (n) and percentage (\%). The comparison between the groups with cancer and venous thrombosis was evaluated by the $\chi 2$ test or the Fisher exact. The significance criteria adopted was the level of 5\%. The statistical analysis was processed by the statistics software SAS ${ }^{\oplus}$ System, version 6.11 (SAS Institute, Inc., Cary, North Carolina).

\section{Results}

Of a total of 14,800 patients, 152 with cancer (breast cancer, $n=16$, prostate cancer, $n=11$, skin cancer, $n=5$, bowel cancer, $n=5$, thyroid cancer, $n=5$, cervix cancer, $n=2$, brain cancer, $n=3$, lymphoma, $n=2$, bone cancer, $n=1$, stomach cancer, $n=1$, larynx cancer, $\mathrm{n}=1$, bladder cancer, $\mathrm{n}=1$, sarcoma, $\mathrm{n}=1$ ) and venous thrombosis (in the lower limb veins, $\mathrm{n}=92$, in the portal vein, $\mathrm{n}=1$, in the 
central venous sinus, $\mathrm{n}=2$, in the ovarian vein, $\mathrm{n}=1$, in the subclavian vein, $\mathrm{n}=1$, in the upper limb veins, $\mathrm{n}=1$ ) were selected (1.02\%). We have used 3 minimum dilation criteria for varicose veins next to the germinating glands in men and in women.

According to Table 1, the mean age in the group with cancer patients was of 63.8 years. In the group with venous thrombosis, the mean age was of 57.4 years. The mean minimum diameter in the entire sample of males was of $2.79 \mathrm{~mm}$ for varicocele to the right of the gland, and of $3.07 \mathrm{~mm}$ for varicocele to the left of the gland. In women, for varicose veins next to the left ovary, the mean diameter was of $5.11 \mathrm{~mm}$, while for varicose veins next to the right ovary, the mean diameter was of $4.87 \mathrm{~mm}$.

\begin{tabular}{|l|c|c|c|c|c|c|}
\hline & \multicolumn{2}{|c|}{ ALL } & \multicolumn{2}{c|}{ Cancer } & \multicolumn{2}{c|}{ Venous Thrombosis } \\
\hline & mean & SD & Mean & SD & Mean & SD \\
\hline In Men & & & & & & \\
\hline Right Varicocele (mm) & 2.76 & 0.99 & 2.59 & 0.81 & 2.81 & 1.06 \\
\hline Left Varicocele (mm) & 3.07 & 1.28 & 2.82 & 1.06 & 3.19 & 1.37 \\
\hline In Women & & & & & & \\
\hline Right Varicocele (mm) & 4.87 & 1.69 & 5.06 & 1.24 & 4.75 & 1.91 \\
\hline Left Varicocele $(\mathrm{mm})$ & 5.11 & 1.92 & 5.46 & 1.52 & 4.89 & 2.10 \\
\hline Total Samples & & & & & & \\
\hline Age (years) & 59.6 & 15.5 & 63.8 & 13.3 & 57.4 & 16.2 \\
\hline
\end{tabular}

SD: Standard Deviation

Table 1: This table provides the mean average and the standard deviation (SD) of veins (in $\mathrm{mm}$ ) in the total sample and by group (cancer and thrombosis)

In accordance with Table 2, when using criteria 1, we have found an increased prevalence of varicose veins next to the germinating glands in the entire sample. The group with cancer has presented a significantly $(\mathrm{p}=0.0029)$ higher proportion of venous dilation (96.3\%) than the group with venous thrombosis $(84.7 \%)$.

\begin{tabular}{|c|c|c|c|c|c|c|c|}
\hline \multirow{2}{*}{} & \multicolumn{2}{|c|}{ All } & \multicolumn{2}{c|}{ Cancer } & \multicolumn{2}{c|}{$\begin{array}{c}\text { Venous } \\
\text { Thrombosis }\end{array}$} & \multirow{2}{*}{ P-value } \\
\cline { 2 - 7 } & $\mathbf{n}$ & $\%$ & $\mathbf{n}$ & $\%$ & $\mathbf{n}$ & $\%$ & \\
\hline Total sample & & & & & & & \\
\hline Criteria 1 & 135 & 88.8 & 52 & 96.3 & 83 & 84.7 & 0.029 \\
\hline Criteria 2 & 107 & 70.4 & 39 & 72.2 & 68 & 69.4 & 0.71 \\
\hline Criteria 3 & 70 & 46.1 & 24 & 44.4 & 46 & 49.9 & 0.77 \\
\hline In Men & & & & & & & \\
\hline Criteria 1 & 59 & 96.7 & 20 & 100 & 39 & 95.1 & 0.99 \\
\hline Criteria 2 & 51 & 836 & 15 & 75.0 & 36 & 87.8 & 0.27 \\
\hline Criteria 3 & 34 & 55.7 & 8 & 40.0 & 26 & 63.4 & 0.084 \\
\hline In Women & & & & & & & \\
\hline Criteria 1 & 76 & 83.5 & 32 & 94.1 & 44 & 77.2 & 0.035 \\
\hline Criteria 2 & 56 & 61.5 & 24 & 70.6 & 32 & 56.1 & 0.17 \\
\hline Criteria 3 & 36 & 39.6 & 16 & 47.1 & 20 & 35.1 & 0.26 \\
\hline In Elders & & & & & & & \\
\hline Criteria 1 & 66 & 89.2 & 32 & 97.0 & 34 & 82.9 & 0.068 \\
\hline Criteria 2 & 49 & 61.5 & 23 & 69.7 & 26 & 63.4 & 0.57 \\
\hline Criteria 3 & 33 & 44.6 & 14 & 42.4 & 19 & 46.3 & 0.74 \\
\hline In not Elders & & & & & & & \\
\hline Criteria 1 & 69 & 88.5 & 20 & 95.2 & 49 & 86.0 & 0.43 \\
\hline Criteria 2 & 58 & 74.4 & 16 & 76.2 & 42 & 73.7 & 0.82 \\
\hline Criteria 3 & 37 & 47.4 & 10 & 47.6 & 27 & 47.4 & 0.98 \\
\hline
\end{tabular}

Criteria 1: Varicocele: between $2.0 \mathrm{~mm}$ and $2.49 \mathrm{~mm}$ and Ovarian Varicocele Veis: between $4.0 \mathrm{~mm}$ and $4.99 \mathrm{~mm}$ Criteria 2: Varicocele: between $2.50 \mathrm{~mm}$ and $2.99 \mathrm{~mm}$ and Ovarian Varicocele Veis: between $5.0 \mathrm{~mm}$ and $5.99 \mathrm{~mm}$ Criteria 3: Varicocele $\geq 3 \mathrm{~mm}$ and Ovarian Varicocele Veis: $\geq 6 \mathrm{~mm}$ $\chi^{2}$ test or Fisher exact.

Table 2: This table provides descriptive data (frequency and percentage) of the criteria (1,2 and 3) for varicose dilation in total according to the group (cancer and venous thrombosis) and the correspondent descriptive level ( $p$ value) of the $\chi 2$ test or the Fisher exact, stratified by sex (men and women) and age group ( $\geq 60$ e $<60$ years) 
When we increased the required values for minimum diameter, as in criteria 2 and 3, we did not find any significant differences in the proportion of varicose dilation. However, the prevalence of ovarian varicose veins and varicocele was persistently high in both pathologies.

In the sub-sample of women, the group with cancer presented a proportion of varicose dilation by criteria 1 (94.1\%) significantly $(\mathrm{p}=0.035)$ higher than the group with venous thrombosis $(77.2 \%)$.

We have proven that the group with cancer presented a significantly $(\mathrm{p}=0.023)$ higher proportion of elders $(61.1 \%)$ than the group with venous thrombosis (41.8\%), according to Table 3.

\begin{tabular}{|c|c|c|c|c|c|c|c|}
\hline & \multicolumn{2}{|c|}{ ALL } & \multicolumn{2}{|c|}{ Cancer } & \multicolumn{2}{|c|}{$\begin{array}{l}\text { Venous } \\
\text { Thrombosis }\end{array}$} & \multirow[t]{2}{*}{ P-value } \\
\hline & $\%$ & $\mathbf{n}$ & $\%$ & $\mathbf{n}$ & $\%$ & $\mathbf{n}$ & \\
\hline \multicolumn{8}{|l|}{ Sex } \\
\hline Male & 61 & 40.1 & 20 & 37.0 & 41 & 41.8 & \multirow{2}{*}{0.56} \\
\hline Female & 91 & 59.9 & 34 & 63.0 & 57 & 58.2 & \\
\hline \multicolumn{8}{|l|}{ Age Group } \\
\hline$\geq 60$ years & 74 & 48.7 & 33 & 61.1 & 41 & 41.8 & \multirow{2}{*}{0.023} \\
\hline$<60$ years & 78 & 51.3 & 21 & 38.9 & 57 & 58.2 & \\
\hline \multicolumn{8}{|l|}{$\chi^{2}$ test } \\
\hline
\end{tabular}

\section{Discussion}

Several studies have shown that varicocele and ovarian varicose veins can increase the risk for phenotypic changes (in the germinating glands), hormonal alterations and infertility [15-18,19,20]. Other researches have also reported that infertility and changes to the hormonal milieu also increase the risk for cancer and venous thrombosis [8,9,25-28].

Beatson and Charles Huggins noticed the role of the ovaries and the testicles in cancer even before sexual hormones were known. In 1895, Beatson [46] performed an oophorectomy in a woman with advanced breast cancer and Charles Huggins, [47] half a century later, executed the removal of the testicles in a man who had advanced prostate cancer. Both noticed the important improvement in their patients as a result of the procedures. This played a fundamental role in the development of hormonal therapy (tamoxifen and aromatase inhibitors) to treat and prevent cancer.

Some other authors have also reinforced the importance of the role played by germinating glands in cancer. This is substantiated by epidemiologic studies that have been performed in the past which featured castrated men and highlighted the role of the testicles in the pathogenesis of prostrate [48]. In addition, it has also been seen that the removal of the ovaries decreases the risk of breast cancer in carriers of the BRCA1 gene (for cancers attributable to the BRCA1 mutation) by approximately 50\% [49].

In addition, it has been reported that changes to the testicles' and ovaries' phenotypes [25,28] increases the risk of cancer and venous thrombosis $[8,9,25-28,50]$. Likewise, epidemiologic data have also demonstrated that venous thrombosis is very frequent in patients with cancer [51].

Furthermore, it is important to highlight that both varicose veins in the lower limbs and varicose veins next to the testicles can be associated to OS [15-18,52-54]. Additionally, varicose veins in the lower limbs may also change the phenotypes of the skin, cause the formation of ulcers, lead to hyperpigmentation and trigger the destruction of tissues [52,53]. Also, varicose veins next to the testicles have been seen to trigger OS, inflammatory processes, decrease glandular volume, alter hormone production, provoke semen abnormalities, cause infertility and change the gland's phenotype [15-18,55,56].

Although there are few studies, it has also been demonstrated that varicose veins next to the ovaries are also associated to OS and to tissue lesions that can cause infertility and hormonal alterations [19,20].

In cases in which phenotypic changes (which could potentially evolve into cancer) cannot be attributed to ovarian varicose veins, but rather to wholly different etiological factors, recent studies have demonstrated that treatment with the chemotherapeutic drug Cisplatin [57-61] can cause premature ovarian and testicular failure and is associated to a high risk of venous thrombosis [62]. This drug also decreases ovarian and testicular reserve by OS [60,61], creating a possibility for the development histologic injuries, infertility, changes in the phenotype of germinating glands and alterations in the hypothalamic-pituitary-gonadal axis.

OS can provoke organ dysfunction, genetic mutations and alterations in angiogenesis $[63,64]$. Studies have shown that there are several genes involved in biological functions, including the regulation of the hypothalamic-pituitary-gonadal axis, the regulation of oncogenes and the coordination of germinating cells. All of these play important roles in the endocrinal system [65,66]. This gain or loss of gene function can be decisive in the development of cancer [67-69]. 
The mutation of the BRCA 1 gene is associated to the reduction of the oocyte and follicle reserve, occult ovarian insufficiency and infertility [70]. We can at least think and pursue further research to investigate if ovarian varicose veins cause most cases of primary ovarian insufficiency, since Pacheco et al have reported that in treating ovarian varicose veins next to the ovaries in two patients with an established diagnosis of premature ovarian failure, both patients began menstruating again [71]. By analogy, the same way varicose veins next to the testicles caused testicular insufficiency [5-7] they could have the same effect on the ovaries.

Three recent studies have shown that OS is higher in varicose veins with insufficient valves [54,72,73]. High levels of OS impair oocyte maturation and contribute to oophoritis and premature ovarian failure $[57,74]$.

A study has also demonstrated that over $50 \%$ of patients with ovarian varicose veins have polycystic ovaries [75] and that the morphologic and functional change in the polycystic ovary syndrome increases the risk of cancer [25], venous thrombosis [76], infertility and cardiovascular problems [77], as well as decreasing the ovarian reserve [25].

This research has demonstrated an expressive prevalence of varicose veins next to the germinating glands, both in the group with cancer patients and in the group with venous thrombosis, regardless of the criteria used.

In the entire sample, the group with cancer has presented a significantly higher $(\mathrm{p}=0.029)$ proportion of varicose dilation in accordance to criteria $1(96.3 \%)$ than the group with venous thrombosis $(84.7 \%)$.

Furthermore, some studies have been showing epidemiologic data which highlight the differences in the prevalence of varicocele in men according to the specific pathology, demonstrating a percentage of $40 \%$ in infertile men(1), $41.7 \%$ in men with increased mean platelet volume (MPV) [78,79], 53\% in men with benign prostate hyperplasia [80], 62\% in men with aneurysms in coronary arteries (ectasia of the coronary arteries) [81] and of $100 \%$ in men prostate cancer [27].

Some authors have demonstrated the frequency of ovarian varicose veins in women by pathology. In women who suffered from chronic pelvic pain, the prevalence was of 50\% [82,83]. In women with endometriosis, the prevalence was of $80 \%$ [84]. In women who had endometriomas in the left ovary, the prevalence was of $100 \%$ [85].

In this study, the authors evidence that the group with cancer contained a significantly $(\mathrm{p}=0.023)$ higher proportion of elders (61.1\%) with varicose veins than the group with venous thrombosis $(41.8 \%)$. This data can be supported by two other studies which have shown that with increasing age, comes an increasing prevalence of varicocele [86,87]. There are also hypotheses that suggest that varicocele can cause a progressive decline in testicular function with increasing age [2]. Medical literature as a whole has also already extensively demonstrated that both aging [2,28] and varicose veins next to the germinating glands [15-18,33] favor hormonal alterations. With that being said, it can be seen that changes in the hormonal milieu could provide important alterations for cancer and venous thrombosis [88-94].

Several authors have reported positive results in treating varicocele in elders with surgery or embolization. The varicocelectomy resulted in an increase of testosterone level $[7,95]$ and the treatment of patients with prostate tumors through embolization resulted in decreases in PSA level, nocturia [95,96], and the volume of the gland. It also has been shown to contribute to the absence of cancer cells in 5 out of 6 patients who have had prostate cancer [27]. Additionally, low serum testosterone levels have also been reported in patients with prostate cancer, especially when the cancer is more aggressive $[27,98,99]$.

The change in ovarian phenotype in menopause [28] and in ovarian insufficiency [89] is associated with increased levels of gonadotropin, decreased ovarian function and a possibility of increasing the risk of cancer [28], endocrine pathologies (such as diabetes and thyroid diseases, among others) and non-endocrine pathologies (such as Lupus and auto-immune hemolytic anaemia, among others) [31,89].

Hormonal interference in the ovary provoked by modern oral contraceptives are able not only to help with contraception but also with other positive effects, such as reducing the rates of endometrial, ovarian and colon rectal cancer [100].

What calls one's attention is the fact that the stimulation of the ovaries for purposes of ovulation with gonadotropin provokes thrombosis in atypical anatomic regions, such as in the jugular vein, the central retinal vein and even in the arteries [94,95].

On the other hand, androgen deficiency with elevated gonadotropin levels and impairment in spermatogenesis increase venous thromboembolisms $[26,101]$.

In this research, in the female subsample, the group with cancer presented a significantly $(\mathrm{p}=0.035)$ higher proportion of varicose dilation in accordance to criteria 1 (94.1\%) than the group with venous thrombosis (77.2\%). By criteria 2 and 3 there was no significant difference, even though the prevalence was still expressive (Table II). It has also already been reported that varicose dilations next to the germinating glands are associated to hormonal alterations [5-7,33]. The rupture of this hormonal balance can exert a fundamental role in the development of cancer and venous thrombosis [8,9,25-28].

In other pathologies (that is, cases of endometrioses that have been associated to hormonal alterations, infertility and cancer) [31], a high prevalence of ovarian varicose veins has been found [85]. Pacheco et al. have also found in patients with endometriosis that the mean minimum diameter of the varicose veins next to the right ovary was of $6.2 \mathrm{~mm}(\mathrm{p}=0.0016)$ and that the mean diameter of the varicose veins next to the left ovary was of $5.8 \mathrm{~mm}(\mathrm{p}=0.0001)$. In this research, in female patients in the group with cancer and venous thrombosis, the mean minimum diameter in the right ovary was of $4.87 \mathrm{~mm}$ and in the left ovary of $5.11 \mathrm{~mm}$. 
The therapeutic test suggests that varicose veins cause destruction of tissue and organs, OS in endothelial cells and, as a result of these damages, the alteration of the expression of several genes [52-54].

For varicose veins in the lower limbs, surgical treatment and the use of compression stockings lead to a decrease in OS and even in the scarring of ulcers [52,53].

In cases of varicocele, varicocelectomies decrease OS next to the testicles, leading to a possibility of the testicles resuming growth $[55,102]$. Moreover, hormone production, sperm production and fertility rates all increase as a result of this procedure [55,102].

The treatment of pelvic varicose veins through embolization has resulted in an improvement in clinic symptomatology and 23 cases of pregnancy reported by several authors [35,39,40,103-105]. These studies suggest that once these pathologies are treated; there is a decrease in OS, an improvement in hormone production, and an increase in ovarian reserve and fertility.

OS present in cancer [25], venous thrombosis [78], varicose veins [52,53,54] and endometriosis [106] plays an important role in these pathologies, interfering with genetics, angiogenesis and in the chronic inflammatory process $[52,53,66]$. However, further research is still needed to confirm that the treatment of varicose veins next to the ovaries and the testicles can prevent, delay, stop or even revert the development of cancer and venous thrombosis and several other pathologies in some patients.

\section{Conclusion}

The group with cancer presented a significantly higher proportion of varicose dilation by criteria 1 than the group with venous thrombosis.

OS present in varicose dilations next to the ovaries and the testicles can alter the phenotype of these glands and interfere in the hypothalamic-pituitary-gonadal axis, leading to changes in the hormonal milieu. This can favour gene mutation in patients with cancer and venous thrombosis.

Information published in medical literature as well as the expressive prevalence of varicocele and ovarian varicose veins in the group of patients with cancer and venous thrombosis made clear to us the necessity of defending a new theory that varicocele and ovarian varicose veins plays an important role in the development of these pathologies.

This article warrants future studies to confirm this theory.

\section{References}

1. Practice Committee of American Society for Reproductive Medicine (2008) Report on varicocele and infertility. Fertil Steril 90: S247-9.

2. Schlegel PN, Goldstein M (2011) Alternate indications for varicocele repair: non-obstructive azoospermia, pain, androgen deficiency and progressive testicular dysfunction. Fertil Steril 96: 1288-93.

3.a. Li F, Chiba K, Yamaguchi K, Okada K, Matsushita K, et al. (2012) Effect of varicocelectomy on testicular volume in children and adolescents: a meta-analysis. Urology 79: 1340-5.

3.b. Diamond DA, Zurakowski D, Bauer SB, Borer JG, Peters CA, et al. (2007) Relationship of varicocele grade and testicular hypotrophy to semen parameters in adolescents. J Urol 178: 1584-8.

4. Gat Y, Zukerman Z, Chakraborty J, Gornish M (2005) Varicocele, hypoxia and male infertility. Fluid Mechanics analysis of the impaired testicular venous drainage system. Hum Reprod 20: 2614-9.

5. Wei TC, Huang WJ, Lin AT, Chen KK (2013) The role of hormones on semen parameters in patients with idiopathic or varicocele-related oligoasthenoteratozoospermia (OAT) syndrome. J Chin Med Assoc 76: 624-8.

6. Guarino N, Tadini B, Bianchi M (2003) The adolescent varicocele: the crucial role of hormonal tests in selecting patients with testicular dysfunction. J Pediatr Surg 38: 120-3.

7. Cayan S, Kadioglu A, Orhan I, Kandirali E, Tefekli A, et al. (1999) The effect of microsurgical varicocelectomy on serum follicle stimulating hormone, testosterone and free testosterone levels in infertile men with varicocele. BJU Int 84: 1046-9.

8. Tvrda E, Agarwal A, Alkuhaimi N (2015) Male reproductive cancers and infertility: a mutual relationship. Int J Mol Sci 16: 7230-60.

9. Jacobsen R, Bostofte E, Engholm G, Hansen J, Olsen JH, et al. (2000) Risk of testicular cancer in men with abnormal semen characteristics: cohort study. BMJ 321: 789-92.

10. Witt MA, Lipshultz LI (1993) Varicocele: a progressive or static lesion. Urology 42: 541-3.

11. Velez de la Calle JF, Rachou E, le Martelot MT, Ducot B, Multigner L, et al. (2001) Male infertility risk factors in a French military population. Hum Reprod 16: 481-6.

12. Mathias SD, Kuppermann M, Liberman RF, Lipschutz RC, Steege JF (1996) Chronic pelvic pain: prevalence, health-related quality of life, and economic correlates. Obstet Gynecol 87: 321-7.

13. Beard RW, Highman JH, Pearce S, Reginald PW (1984) Diagnosis of pelvic varicosities in women with chronic pelvic pain. Lancet 2: $946-9$.

14. Barros FS, Perez JMG, Zandonade E, Salles-Cunha SX, Monedero J, et al. (2010) Evaluation of pelvic varicose veins using color Doppler ultrasound: comparison of results obtained with ultrasound of the lower limbs, transvaginal ultrasound, and phlebography. J Vasc Bras 915-23.

15. Allamaneni SS, Naughton CK, Sharma RK, Thomas AJ Jr, Agarwal A (2004) Increased seminal reactive oxygen species levels in patients with varicoceles correlate with varicocele grade but not with testis size. Fertil Steril 82 1684-6.

16. Mancini A, Meucci E, Milardi D, Giacchi E, Bianchi A, et al. (2004) Seminal antioxidant capacity in pre- and postoperative varicocele. J Androl 25: 44-9.

17. Saleh RA, Agarwal A, Sharma RK, Said TM, Sikka SC, et al. (2003) Evaluation of nuclear DNA damage in spermatozoa from infertile men with varicocele. Fertil Steril 80: 1431-6. 
18. Benoff SH, Millan C, Hurley IR, Napolitano B, Marmar JL (2004) Bilateral increased apoptosis and bilateral accumulation of cadmium in infertile men with left varicocele. Hum Reprod 19: 616-27.

19. Heydari L, Mugahi SMHN, Fazelipour S, Koruji M, Alizadeh R, et al. (2015) Effects of Ovarian Varicose Vein on Mitochondrial Structure, Malondialdehyde and Prooxidants: Antioxidants Balance in Rat. Int J Morphol 33: 930-5.

20. Kehinde BA, Abolhassani F, Yazdekhasti H, Abbasi N, Heydari L, et al. (2016) The effects of unilateral varicose ovarian vein on antioxidant capacity and oocyte quality in rat ovary. Iran J Basic Med Sci 19: 863-9.

21. Harvey AJ, Kind KL, Thompson JG (2002) Redox regulation of early embryo development. Reproduction 123: 479-86.

22. Aitken RJ, Baker MA, Sawyer D (2003) Oxidative stress in the male germ line and its role in the aetiology of male infertility and genetic disease. Reprod Biomed Online 7: 65-70.

23. Ji BT , Shu XO, Linet MS, Zheng W, Wacholder S, et al. (1997) Paternal cigarette smoking and the risk of childhood cancer among offspring of nonsmoking mothers. J Natl Cancer Ins 89: 238-44.

24. Saleh RA, Agarwal A, Sharma RK, Said TM, Sikka SC, et al. (2003) Evaluation of nuclear DNA damage in spermatozoa from infertile men with varicocele. Fertil Steril 80: 1431-6.

25. Zuo T, Zhu M, Xu W (2016) Roles of Oxidative stress in polycystic ovary syndrome and cancers. Oxid Med Cell Longev 10.1155/2016/8589318.

26. Lapecorella M, Marino R, De Pergola G, Scaraggi FA, Speciale V, et al. (2003) Severe venous thromboembolism in a young man with Klinefelter's syndrome and heterozygosis for both G20210A prothrombin and factor V Leiden mutations. Blood Coagul Fibrinolysis 14: 95-8.

27. Gat Y, Joshua S, Gornish MG (2009) Prostate cancer: a newly discovered route for testosterone to reach the prostate: Treatment by super-selective intraprostatic androgen deprivation. Andrologia 41: 305-15

28. Schiffenbauer YS, Abramovitch R, Meir G, Nevo N, Holzinger M, et al. (1997) Loss of ovarian function promotes angiogenesis in human ovarian carcinoma. Proc Natl Acad Sci USA 94: 13203-8.

29. Everarts P, Poelaert D, Bormans P, Guisgand M, Debehogne G, et al. (2008) Pelvic varicose veins thrombosis in a patient with pulmonary. JBR-BTR 91: 200-2. 30. Benfayed WH, Torreggiani WC, Hamilton S (2003) Detection of pulmonary emboli resulting from ovarian vein thrombosis. AJR Am J Roentgenol 181: 1430-1. 31. Tarín JJ, García-Pérez MA, Hamatani T, Cano A (2015) Infertility etiologies are genetically and clinically linked with other diseases in single meta-diseases. Reprod Biol Endocrinol 13: 31 .

32. Buis CC, van Leeuwen FE, Mooij TM, Burger CW, OMEGA Project Group (2013) Increased risk for ovarian cancer and borderline ovarian tumours in subfertile women with endometriosis. Hum Reprod 28: 3358-69.

33. Asciutto G, Mumme A, Asciutto KC, Geier B (2010) Oestradiol Levels in varicose vein blood of patients with and without pelvic vein incompetence (PVI): diagnostic implications. Eur J Vasc Endovasc Surg 40: 117-21.

34. Kuligowska E, Deeds L III, Lu K III (2005) Pelvic pain: overlooked and underdiagnosed gynecologic conditions. Radiographics 25: 3-20.

35. Galkin EV, Grakova LS, Naumova EB (1991) Roentgeno-endovascular surgery of hypofunctional ovaries in varicosities of the ovarian veins. Vestn Rentgenol Radiol 5: 51-9.

36. Hamm B, Fobbe F, Sörensen R, Felsenberg D (1986) Varicoceles: Combined sonography and thermography in diagnosis and post therapeutic evaluation Radiology 160: 419-24.

37. Rifkin MD, Foy PM, Kurtz AB, Pasto ME, Goldberg BB (1983) The role of diagnostic ultrasonography in varicocele evaluation. J Ultrasound Med 2: 271-5.

38. Wolverson MK, Houttuin E, Heiberg E, Sundaram M, Gregory J (1983) High-resolution real-time sonography of scrotal varicocele. AJR Am J Roentgenol 141: 775-9.

39. Kim HS, Malhotra AD, Rowe PC, Lee JM, Venbrux AC (2006) Embolotherapy for pelvic congestion syndrome: long-term results. J Vasc Interv Radiol 17: 28997.

40. Monedero JL, Ezpeleta SZ, Perrin M (2012) Pelvic congestion syndrome can be treated operatively with good long-term results. Phlebology 27: 65-73.

41. Ratnam LA, Marsh P, Holdstock JM, Harrison CS, Hussain FF, et al. (2008) Pelvic vein embolisation in the management of varicose veins. Cardiovasc Intervent Radiol 31: 1159-64.

42. Petros JA, Andriole GL, Middleton WD, Picus DA (1991) Correlation of testicular color Doppler ultrasonography, physical examination and venography in the detection of left varicoceles in men with infertility. J Urol 145: 785-8.

43. Labropoulos N, Tiongson J, Pryor L, Tassiopoulos AK, Kang SS, et al. (2003) Definition of venous reflux in lower-extremity veins. J Vasc Surg 38: 793-8.

44. Engelhorn CA, Morais Filho D, Barros FS, Coelho NA (2006) Guia prático de ultra-sonografia vascular. Rio de Janeiro: Dilivros, Brazil.

45. Thomaz JB, Belczack CEQ (2006) Recidiva varicosa de etiologia pélvica In: Tratado de flebologia e linfologia. Rio de Janeiro: Livraria Rubio, Brazil.

46. Beatson GTh (1896) On the treatment of inoperable cases of carcinoma of the mamma: suggestions for a new method of treatment, with illustrative cases. The Lancet 148: 162-5.

47. Huggins C (1967) Endocrine-induced regression of cancers. Cancer Res 27: 1925-30.

48. Rove KO, Crawford ED (2005) Traditional androgen ablation approaches to advanced prostate cancer: new insights. Can J Urol 21 : 14-21.

49. Rebbeck TR, Levin AM, Eisen A, Snyder C, Watson P, et al. (1999) Breast Cancer Risk After Bilateral Prophylactic Oophorectomy in BRCA1 Mutation Carriers. J Natl Cancer Inst 91: 1475-9.

50. Swerdlow AJ, Schoemaker MJ, Higgins CD, Wright AF, Jacobs PA, et al. (2005) Cancer Incidence and mortality in men with klinefelter syndrome: a cohort study. J Natl Cancer Inst 97: 1204-10.

51. Blom JW, Doggen CJ, Osanto S, Rosendaal FR (2005) Malignancies, prothrombotic mutations, and the risk of venous thrombosis. JAMA 293: 715-22.

52. Murphy MA, Joyce WP, Condron C, Bouchier-Hayes D (2002) A reduction in serum cytokine levels parallels healing of venous ulcers in patients undergoing compression therapy. Eur J Vasc Endovasc 23: 349-52.

53. Flore R, Santoliquido A, Antonio DL, Pola E, Flex A, et al. (2003) Long saphenous vein stripping reduces local level of reactive oxygen metabolites in patient s with varicose disease of the lower limbs. World J Surg 27: 473-5.

54. Horecka A, Biernacka J, Hordyjewska A, Dąbrowski W, Terlecki P, et al. (2017) Antioxidative mechanism in the course of varicose veins. Phlebology $10.1177 / 0268355517721055$ 
55. Tanrikut C, Goldstein M, Rosoff JS, Lee RK, Nelson CJ, et al. (2011) Varicocele as a risk factor for androgen deficiency and effect of repair. BJU Int 108: 1480-4. 56. Prasivoravong J, Marcelli F, Lemaître L, Pigny P, Ramdane N, et al. (2014) Beneficial effects of varicocele embolization on semen parameters. Basic Clin Androl 24.

57. Starling N, Rao S, Cunningham D, Iveson T, Nicolson M, et al. (2009) Thromboembolism in patients with advanced gastroesophageal cancer treated with anthracycline, platinum, and fluoropyrimidine combination chemotherapy: A report from the UK National Cancer Research Institute Upper Gastrointestinal Clinical Studies Group. J Clin Oncol 27: 3786-93.

58. Al-Batran SE, Hartmann JT, Probst S, Schmalenberg H, Hollerbach S, et al. (2008) Phase III trial in metastatic gastroesophageal adenocarcinoma with fluorouracil, leucovorin plus either oxaliplatin or cisplatin: a study of the Arbeitsgemeinschaft Internistische Onkologie. J Clin Oncol 26: 1435-2.

59. Xiaohuan Li, Shu Yang, Xiangyang Lv, Haimei Sun, Jing Weng, et al. (2013) The mechanism of mesna in protection from cisplatin-induced ovarian damage in female rats. J Gynecol Onco 24: 177-85.

60. Aksu EH, Kandemir FM, Özkaraca M, Ömür AD, Küçükler S, et al. (2017) Rutin ameliorates cisplatin-induced reproductive damage via suppression of oxidative stress and apoptosis in adult male rats. Andrologia 49.

61. Vassilakopoulou M, Boostandoost E, Papaxoinis G, de La Motte Rouge T, Khayat D, et al. Anticancer treatment and fertility: Effect of therapeutic modalities on reproductive system and functions. Crit Rev Oncol Hematol 97: 328-34.

62. Moore RA, Adel N, Riedel E, Bhutani M, Feldman DR, et al. (2011) High incidence of thromboembolic events in patients treated with Cisplatin-based chemotherapy: a large retrospective analysis. J Clin Oncol 29: 3466-73.

63. Martins PS, Kallas EG, Neto MC, Dalboni MA, Blecher S, et al. (2003) Upregulation of reactive oxygen species generation and phagocytosis, and increased apoptosis in human neutrophils during severe sepsis and septic shock. Shock 20: 208-12.

64. Ohura N, Yamamoto K, Ichioka S, Sokabe T, Nakatsuka H, et al. (2003) Global analysis of shear stress-responsive genes in vascular endothelial cells. J Atheroscler Thromb 10: 304-13.

65. El Sadek MM, Amer MK, Fahmy M (1998) Acute cerebrovascular accidents with severe ovarian hyperstimulation syndrome. Hum Reprod 13: 1793-5.

66. Dixit H, Rao L, Padmalatha V, Raseswari T, Kapu AK, et al. (2010) Genes governing premature ovarian failure. Reprod Biomed Online 20: 724-40.

67. Hanahan D, Weinberg RA (2000) The hallmarks of câncer. Cell 100: 57-70.

68. Vogelstein B, Kinzler KW (2004) Cancer genes and the pathways they control. Nat Med 10: 789-99.

69. Boccaccio C1, Sabatino G, Medico E, Girolami F, Follenzi A, et al. (2005) The MET oncogene drives a genetic programme linking cancer to haemostasis. Nature 434: 396-400.

70. Wang ET, Pisarska MD, Bresee C, Chen YD, Lester J, et al. (2014) BRCA1 germline mutations may be associated with reduced ovarian reserve. Fertil Steril 102: 1723-8.

71. Kennedy Gonçalves Pacheco and Raquel Fortes. (2015) Ovarian Varicose Veins may Provoke Premature Ovarian Failure? EC Gynaecol 2: 156-62.

72. Krzyściak, W., Kózka, M (2011) Generation of reactive oxygen species by a sufficient, insufficient and varicose vein wall. Acta Biochim Pol 58: 89-94.

73. Karatepe O, Unal O, Ugurlucan M, Kemik A, Karahan S, et al. (2010) The impact of valvular oxidative stress on the development of venous stasis ulcer valvular oxidative stress and venous ulcers. Angiology 61: 283-8.

74. Kumar M, Pathak D, Kriplani A, Ammini AC, Talwar P, et al. (2010) Nucleotide variations in mitochondrial DNA and supraphysiological ROS levels in cytogenetically normal cases of premature ovarian insufficiency. Arch Gynecol Obstet 282: 695-705.

75. Ignacio EA, Dua R, Sarin S, Anthony C, Venbrux (2008) Pelvic Congestion Syndrome: Diagnosis and Treatment. Semi Intervent Radiol 25: 361-8.

76. Okoroh EM, Hooper WC, Atrash HK,Yusuf HR (2012) Is polycystic ovary syndrome another risk factor for venous thromboembolism? United States, 2003 2008. Am J Obstet Gynecol 207: 377.e1-8.

77. Wiltgen D, Spritzer PM (2010) Variation in metabolic and cardiovascular risk in women with different polycystic ovary syndrome phenotypes. Fertil Steril 94 : 2493-6.

78. Coban S, Keles I, Ocak N (2015)“Does Varicocele Correction Lead to Normalization of Preoperatively Elevated Mean Platelet Volume Levels?” Canad Urol Assoc 9: E5-E9.

79. Bozkurt Y, Soylemez H, Sancaktutar AA, Islamoglu Y, Kar A, et al. (2012) Relationship between mean platelet volume and varicocele: a preliminary study. Urology 79: 1048-51.

80. Han H, Yu ZX, Gong LI, Lu RG, Li MQ, et al. (2016) The Prevalence and Association of Varicoceles on Male Patients With Benign Prostatic Hyperplasia/Lower Urinary Tract Symptoms. Urology 90: 97-100.

81. Yetkin E, Kilic S, Acikgoz N, Ergin H, Aksoy Y (2005) Increased prevalence of varicocele in patients with coronary artery ectasia. Coron Artery Dis 16: 261-4.

82. Giacchetto C, Cotroneo GB, Marincolo F, Cammisuli F, Caruso G, et al. (1990) Ovarian varicocele: ultrasonic and phlebographic evaluation. J Clin Ultrasound 18: 551-5.

83. Park SJ, Lim JW, Ko YT, Lee DH, Yoon Y, et al. (2004) Diagnosis of pelvic congestion syndrome using transabdominal and transvaginal sonography. Am J Roentgenol 182: 683-8.

84. Pacheco KG,Oliveira MR (2016)The Prevalence of Ovarian Varices in Patients with Endometriosis. Annals of Vascular Surgery 34 : 135-43.

85. Matalliotakis IM, Cakmak H, Koumantakis EE, Margariti A, Neonaki M, et al. ( 2009) Arguments for a left lateral predisposition of endometrioma. Fertil Steril 91: $975-8$.

86. Canales BK, Zapzalka DM, Ercole CJ, Carey P, Haus E, et al. (2005) Prevalence and effect of varicoceles in an elderly population. Urology 66: 627-31.

87. Levinger U, Gornish M, Gat Y, Bachar GN (2007) Is varicocele prevalence increasing with age? Andrologia 39: 77-80.

88. Goswami D, Conway GS (2007) Premature Ovarian Failure. Horm Res Paediatr 68: 196-202.

89. Elford K, Leader A, Wee R, Stys PK (2002) Stroke in ovarian hyperstimulation syndrome in early pregnancy treated with intra-arterial rt-PA. Neurology 59: $1270-2$.

90. Chatterjee B (2003) The role of the androgen receptor in the development of prostatic hyperplasia and prostate cancer. Mol Cell Biochem 253: 89-101.

91. Labrie F, Luu TV, Be'langer A, Lin SX, Simard J, et al. (2005) Is dehydroepiandrosterone a hormone? J Endocrinol 187: 169-96. 
92. Rebbeck TR, Levin AM, Eisen A, Snyder C, Watson P, et al. (1999) Breast Cancer Risk After Bilateral Prophylactic Oophorectomy in BRCA1 Mutation Carriers . J Natl Cancer Inst 91: 1475-9.

93. El Sadek MM, Amer MK, Fahmy M (1998) Acute cerebrovascular accidents with severe ovarian hyperstimulation syndrome. Hum Reprod 13 : $1793-5$.

94. Stewart JA, Hamilton PJ, Murdoch AP (1997) Thromboembolic disease associated with ovarian stimulation and assisted conception techniques. Hum reprod 12: $2167-73$.

95. Hsiao W, Rosoff JS, Pale JR, Greenwood EA, Goldstein M (2011) Older age is associated with similar improvements in semen parameters and testosterone after subinguinal microsurgical varicocelectomy. J Urol 185: 620-5.

96. Gat Y, Gornish M, Heiblum M, Joshua S (2008) Reversal of benign prostate hyperplasia by selective occlusion of impaired venous drainage in the male reproductive system: novel mechanism, new treatment. Andrologia 40: 273-81.

97. Morgentaler A, Bruning CO, DeWolf WC (1996) Occult prostate cancer in men with low serum testosterone levels. JAMA 276: 1904-06.

98. Hoffman MA, DeWolf WC, Morgentaler A (2000) Is low serum free testosterone a marker for high grade prostate cancer? J Urol 163: 824-7.

99. The American College of Obstetricians and Gynecologists (2010) ACOG Practice Bulletin No. 110: noncontraceptive uses of hormonal contraceptives. Obstet Gynecol 115: 206-18.

100. Campbell WA, Price WH (1981) Venous thromboembolic disease in Klinefelter's syndrome. Clin Genet 19: 275-80.

101. Chen SS, Huang WJ, Chang LS, Wei YH (2008) Attenuation of oxidative stress after varicocelectomy in subfertile patients with varicocele. J Urol 179: 639-42. 102. Tarazov P, Prozorovskij K, Rumiantseva S (2011) Pregnancy after embolization of an ovarian varicocele associated with infertility: report of two cases. Diagn Interv Radiol 17: 174-6.

103. Venbrux AC, Chang AH, Kim HS, Montague BJ, Hebert JB, et al. (2002) Pelvic congestion syndrome (pelvic venous incompetence): impact of ovarian and internal iliac vein embolotherapy on menstrual cycle and chronic pelvic pain. J Vasc Interv Radiol 13: 171-8.

104. Bachar GN, Belenky A, Greif F, Atar E, Gat Y (2003) Initial experience with ovarian vein embolization for the treatment of chronic pelvic pain syndrome. Isr Med Assoc J 5: 843-6.

105. Wu YK Balla AK, Strawn E, Basir Z, Halverson G, Jailwala P, et al. (2006) Transcriptional characterizations of differences between eutopic and ectopic endometrium. Endocrinology 147: 232-46.

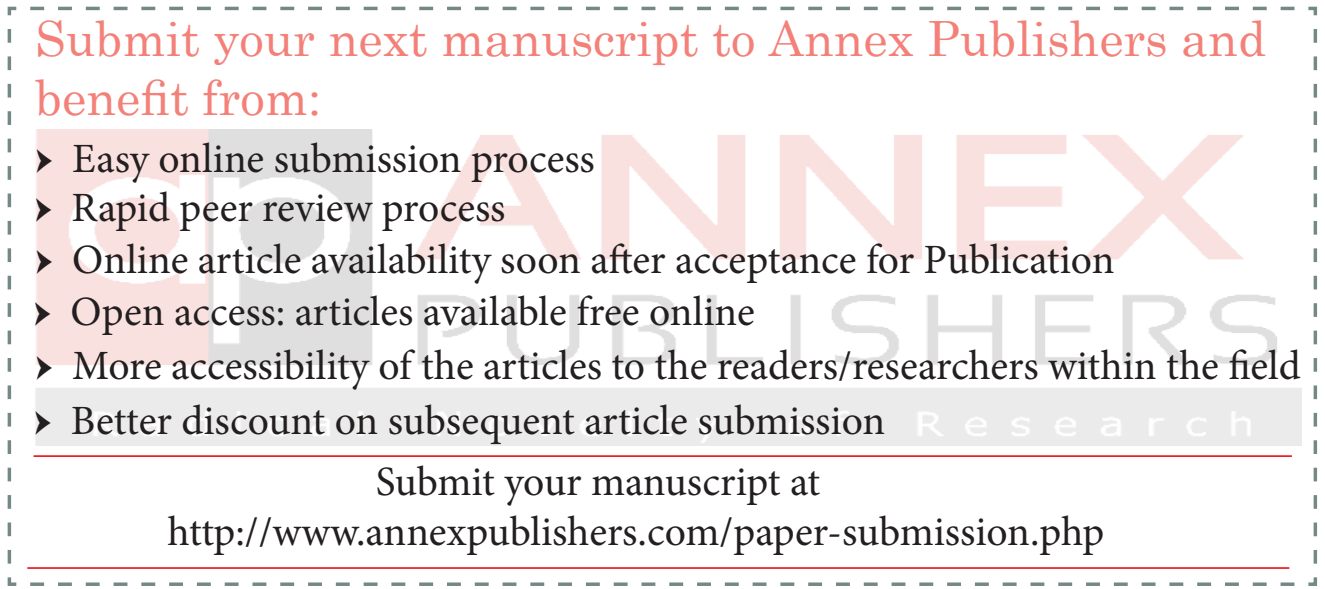

